\title{
Evaluation of the retina and optic nerve after the use of stem cells for neurodegenerative disorders in an animal model
}

\section{Estudio de la retina y el nervio óptico tras el uso de células madre en enfermedades neurodegenerativas en un modelo animal}

\author{
Romana García-Gil1*, Anselmo Feliciano-Sanchez ${ }^{1}$, Laura Cubas-Nuñez², Jessica Castillo-Villalba², \\ Jorge Fuentes-Maestre ${ }^{3}$, Mariana Fil ${ }^{3}$, Jose M. García-Verdugo ${ }^{3,4}$ and Sara Gil-Perotin ${ }^{5 *}$ \\ 'Ophthalmology department, Medical and Surgical Retina Unit, Hospital Universitario y Politécnico La Fe; ${ }^{2}$ Neuroimmunology and Neuronal \\ Regeneration, Instituto de Investigación Sanitaria La Fe; ${ }^{3}$ Department of Cell Biology and Parasitology, Universidad de Valencia; ${ }^{4}$ Department of \\ Comparative Neurobiology, Universidad de Valencia; ${ }^{5}$ Department of Neurology, Mixed Unit of Multiple Sclerosis and Neuroregeneration, Hospital \\ Universitario y Politécnico La Fe. Valencia, Spain
}

\begin{abstract}
Objective: To study the neuroprotective and neuroregenerative response of adult mesenchymal cells (aMSCs) on retinal ganglion cells (RGC) and optic nerve (ON) in an animal model of multiple sclerosis (MS) like experimental autoimmune encephalitis (EAE). Methods: We studied the changes that occurred in the retina and ON, analyzing the effect of an intravenous injection of aMSCs. Three groups were studied: healthy (control), sick (EAE) and sick treated with aMSCs (EAE-MSC). The animals were monitored using motor disability scales. The retinas and ONs were studied with optical microscopy, immunofluorescence and electron microscopy. Results: The results showed that after administration of intravenous aMSCs there was a lower loss of RGC, the average of RGC in the EAE group was of $0.0891 \mu \mathrm{m}$ compared to $0.166 \mu \mathrm{m}$ in the EAE-MSC group, with a statistically significant $p$ value $(p=0.01)$. There was a reduction in the inflammatory cell response of the $O N$ (7.99 cells/ $/ \mathrm{m}^{2}$ vs. 3.69 cells $/ \mu m^{2}, p<0.0001$ ), a decrease of myelin loss (overall axonal damage was of $54 \%$ compared to $88 \%)$ and less axonal destruction $\left(0.16745\right.$ axons $/ \mu m^{2}$ vs. 0.3598 axons $/ \mu m^{2}(p=0.0251)$. Conclusions: In this study, we found that after the administration of aMSCs there was a lower loss of RGC, a decrease of myelin loss and a lower degree of inflammation in the ON. However, it would be advisable to expand the methodology to ensure an immunosuppressive and neuroprotective effect in this model.
\end{abstract}

Key words: Optic neuritis. Experimental autoimmune encephalitis. Mesenchymal cells. Neuroprotection. Immunomodulation.

\section{Resumen}

Objetivo: Estudiar la respuesta neuroprotectora y neurorregeneradora de las células mesenquimales adultas (aMSC) sobre las células ganglionares de la retina (CGR) y el nervio óptico (NO) en un modelo animal de esclerosis múltiple, como la

\footnotetext{
Correspondence:

*Romana García-Gil

Luis Bolinches, 27-10. ${ }^{a} \mathrm{C}$

C.P. 46023 , Valencia, Spain

E-mail: Romygg9@ hotmail.com

Date of reception: 08-03-2019

Date of acceptance: 18-07-2019

E-mail: sara.garcia@uv.es

DOI: 10.24875/RMOE.M19000086 2604-1731/O 2019 Sociedad Mexicana de Oftalmología. Published by Permanyer México SA de CV. This is an open access article under the CC BY-NC-ND license (http://creativecommons.org/licenses/by-nc-nd/4.0/).
} 
encefalitis autoinmune experimental (EAE). Métodos: Se estudiaron los cambios que ocurrieron en la retina y el NO, se analizó el efecto de la inyección endovenosa de células mesenquimales. Se estudiaron tres grupos: sanos (control), enfermos (EAE), enfermos en tratamiento con aMSC (EAE-MSC). Los animales fueron monitorizados y seguidos mediante escalas de discapacidad motora. Las retinas y nervios ópticos se procesaron para: microscopia óptica, inmunofluorescencia y microscopia electrónica. Resultados: Los resultados demostraron que tras la administración de aMSC intravenosas se producía una menor pérdida de CGR, el promedio de CGR en el grupo EAE fue de $0.0891 \mu \mathrm{m}$, frente $0.1166 \mu \mathrm{m}$ del grupo EAE-MSC, con un valor de $p$ estadísticamente significativo $(p=0.01)$. Se producía una reducción de la respuesta celular inflamatoria en el NO (7.99 células $/ \mu m^{2}$ frente 3.69 células $/ \mu m^{2} ; p<0.0001$ ), disminución de la pérdida de mielina (el daño axonal global se reduciría al $54 \%$ frente al $88 \%$ ) y menor destrucción axonal (0.16745 axones $/ \mu m^{2}$ frente 0.3598 axones $/ \mu m^{2} ; p=0.0251$ ). Conclusiones: En este trabajo, encontramos tras la administración de aMSC, una menor pérdida de CGR, disminución de la pérdida de mielina y menor grado de inflamación en el NO; sin embargo, sería aconsejable ampliar la metodología para poder asegurar un efecto inmunosupresor y neuroprotector en este modelo.

Palabras clave: Neuritis óptica. Encefalitis autoinmune experimental. Células mesenquimales. Neuroprotección. Inmunomodulación.

\section{Introduction}

Multiple sclerosis (MS) is considered one of the most common causes of neurological disability in young adults. It is a chronic and inflammatory disease of the central nervous system (CNS), characterized by axonal demyelination, gliosis and neuronal degeneration. A pathogenic hypothesis relates MS with dysimmune responses, with the participation of innate autoantibodies, complement and mediators of immune response'. Immunosuppressive drugs are considered disease-modifying therapies, as they can reduce disability, relapse frequency, severity and duration of symptoms.

Unfortunately, disease-modifying therapies are not curative and sometimes do not prevent progressive courses or progression of disability².

Cell therapies represent a new frontier in the treatment of neurological diseases. In this context, adult mesenchymal stem cells (aMSC) have demonstrated their therapeutic potential in various disease models, since aMSCs behave heterogeneously according to the tissue of origin and the culture conditions. The International Society for Cell Therapy in 2006, established guidelines for their characterization according to three criteria ${ }^{3:}$ 1) growth adhering to the plastic surfaces used for culture; 2) expression of surface molecules (CD73, CD90 and CD105), and the absence of monocyte and macrophage markers (CD11b and CD14), leukocyte marker (CD45), B cell marker (CD19 or CD79a), hematopoietic parent marker and endothelial cell markers (CD34), and HLA-DR; and 3 ) in vitro differentiation potential towards osteoblasts, adipocytes and chondroblasts.

The benefit exerted by aMSCs has been associated with the ability to differentiate into several cell lineages, segregate soluble factors crucial to cell proliferation and survival ${ }^{4}$, modulate the immune response ${ }^{5}$ and migrate to the site of injury 6 . Since tissue damage due to inflammation is a key process triggered in response to injury and disease, aMSCs could become a treatment for any tissue or organic damage associated with an intense inflammatory activity ${ }^{5}$.

Multiple models of MS have been designed in experimental research to achieve a better understanding of the pathogenesis of the disease and the mechanisms of progression. Encephalomyelitis (experimental autoimmune encephalitis, EAE) is an animal model of MS based on active immunization that clinically reproduces the inflammatory lesions that occur in MS. Optic neuritis, an inflammation of the optic nerve (ON) and progressive spinal cord injury have been described in B6/ C57 mice after immunization with a fragment of the myelinic oligodendrocyte glycoprotein (MOG) comprising 35 to 55 amino acid residues $\left(\mathrm{MOG}_{35-55}\right)$. This induces demyelination with posterior axonal damage and neuronal loss that also affects the eye, particularly retinal ganglion cells (RGC) $)^{7}$. In fact, it has been shown that the severity of EAE correlates with the signs of demyelination and inflammation of the $\mathrm{ON}^{3}$.

\section{Objective}

To study the neuroprotective and neuro-regenerative response of aMSCs on RGC and the ON in an animal model of MS.

\section{Material and Methods}

\section{Animals}

Twenty-four female B6/C57 mice, 10 weeks old. The animals were divided into three groups: a control group (10 animals), an EAE group (7 animals) and an 
EAE-MSC group (animals with EAE treated with aMSCs, administered intravenously; 7 animals). The possible effects of aMSCs injection in control animals were ruled out during the development and optimization process of the animal model. These animals were used for experimentation according to the ethical guidelines for animal experimentation. Animals with EAE were injected with $\mathrm{MOG}_{35-55}(200 \mu \mathrm{g}$ of peptide/animal, $200 \mu \mathrm{l}$ intraperitoneally $)^{9}$, monitored every $24-48 \mathrm{~h}$ and had a motor disability evaluation performed. The EAE-MSC group was injected with $1 \times 10^{6}$ aMSCs $^{10}$ together with a green fluorescent protein (GFP) intravenously into the tail vein. We considered the onset of the disease as the appearance of weakness of the distal tail and/or the presence of a slight irregular movement. When the animals met the endpoint criteria (when the animal was unable to get food or water), they were euthanized. Subsequently, they were perfused through the left ventricle of the heart with $50 \mathrm{ml}$ of sterile saline solution $(0.9 \% \mathrm{NaCl})$, followed by $150 \mathrm{ml}$ of $4 \%$ paraformaldehyde (PFA) or $2 \%$ glutaraldehyde, 2.5\% PFA solution. Later, the eyeballs and the ON were removed and subsequently fixed in the same fixative for $24 \mathrm{~h}$. Then, they were washed with $0.1 \mathrm{M}$ phosphate buffered saline (PBS) $0.1 \mathrm{M}$. Finally, the samples were kept at $4{ }^{\circ} \mathrm{C}$ in $1.1 \mathrm{M}$ PBS with $0.05 \%$ sodium azide to avoid bacterial and fungal contamination.

\section{Growth, characterization and transfection of adult mesenchymal stem cells with fluorescent green protein}

All the samples were collected after plastic surgery of patients that underwent elective lipoaspirate procedures at the Cervera Sebastián Clinic (Valencia, Spain). An informed consent form was given to the patients to be signed and stored in the CELULIFE database, after receiving information about the study. The use of adipose tissue samples was approved by the corresponding Ethics Committee (CAEC, Autonomous Committee of Clinical Trials, Valencia, Spain). The participants did not receive a financial compensation. At all times, the study followed the laws and regulations in force, including the ethical principles derived from the Declaration of Helsinki, the international policy on conducting clinical studies in the International Guidelines for Ethical Review of Epidemiological Studies (Council for the International Organizations of Medical Sciences-CIOMS-Geneva, 2009) and Recommendations on Good Clinical Practice.

Isolation of stem cells derived from adipose tissue was carried out using a mechanical and enzymatic method. The digestion mixture was composed of
Dulbecco's Phosphate-Buffered Saline (DPBS) pH 7.5 (Life technologies Cat No.10010056) with $1 \mathrm{mg} / \mathrm{mL}$ collagenase type I (Gibco Cat No. 17100-017) and the same volume of aspirated adipose tissue. The tissue was digested for 30 minutes at $37^{\circ} \mathrm{C}$ under stirring and then filtered to separate undigested tissue and centrifuged at $500 \mathrm{~g}$ for 10 minutes at room temperature. The supernatant (floating adipocytes) was separated from the sediment (fraction of stem cells derived from adipose tissue). The cells were resuspended in an erythrocyte lysis buffer (BD Cat \# 555900), incubated at room temperature for 10 minutes and centrifuged at $500 \mathrm{~g}$ for 10 minutes at $20^{\circ} \mathrm{C}$. Finally, the cells were resuspended and expanded in Dulbecco's Modified Eagle Medium (DMEM) culture medium with low glucose content (Gibco 31885023$)$, supplemented with $10 \%$ human serum and $1 \%(\mathrm{v} / \mathrm{v})$ penicillin/streptomycin $(10,000 \mathrm{U} / \mathrm{mL}$ penicillin, $10,000 \mu \mathrm{g} / \mathrm{mL}$ streptomycin, Gibco Life Technologies, No. 15140-122). Stem cells derived from adipose tissue were grown at $37{ }^{\circ} \mathrm{C}$ in an air atmosphere with $5 \% \mathrm{CO} 2$, with medium change every 3 days. When the cells reached approximately $80 \%$ confluence in the flask, the subculture (passage) was performed by trypsinization, counted and reseeded in a T75 cell culture plate treated with polylysine for monolayer cell growth at a density of $5,000 \mathrm{cells} / \mathrm{cm}^{2}$. For trypsinization, the culture medium was aspirated, and the flask was washed using PBS. Then, the solution was discarded, and trypsin was added ( $6 \mathrm{~mL} /$ flask) and left for 5 minutes. Trypsin was neutralized using the same amount of complete medium. The cell suspension was centrifuged (500 g for 7 minutes) and its supernatant was aspirated. The sediment was resuspended in complete medium and the cells were counted using the trypan blue exclusion test (hemocytometer). In the fourth step, they were transfected by electroporation with a plasmid expressing GFP. The expression vector was constructed by inserting the commercially obtained empty vector (Invitrogen) PCEP4 into the GFP gene. The plasmid was introduced at the appropriate concentration, and 24 hours later it was possible to determine the effectiveness of the process by fluorescence detection. This plate was incubated for 3 days at $37{ }^{\circ} \mathrm{C}$ with $5 \% \mathrm{CO} 2$. The cells were fully characterized as aMSCs by immunophenotype with flow cytometry ${ }^{11}$.

\section{Processing of the optic nerve and retina for histological study}

Longitudinal sections of the eyeball $(400 \mu \mathrm{m}$ thick) were obtained with a vibratome (Vibratome Leica 
Biosystems $1000 \mathrm{mM})$. The ON sections were selected at the point where it exits the eyeball and underwent two different procedures: 1) cryoprotection in $30 \%$ sucrose, followed by rapid freezing with liquid nitrogen and $10 \mu \mathrm{m}$ sectioning with a cryostat (CM1900, Leica, Heidelberg, Germany), followed by staining with hematoxylin-eosin and toluidine blue; 2) inclusion in epoxy resin followed by $1.5 \mu \mathrm{m}$-semifine sectioning with an ultramicrotome (Ultracut, Leica ultracut-MZ6). Resident and reactive glia was detected in frozen $10 \mu \mathrm{m}$ sections by immunoblotting with rabbit polyclonal antibody anti-GFAP (glial fibrillary acidic protein) (\# 12692777, Fisher Scientific, Hampton, New Hampshire, USA) diluted 1:200, incubated with diluted blocking buffer (5\% normal goat serum (NGS), $5 \%$ casein in PBS) overnight at $4{ }^{\circ} \mathrm{C}$. The samples were washed in $0.1 \mathrm{M} \mathrm{PB}$, and incubation of the secondary antibody (goat anti-rabbit alexa 555, \# A21428, Fisher Scientific) diluted 1:500 in $5 \%$ (NGS) PBS was carried out for 1 hour at room temperature, conjugated with fluorescence. The samples were then washed in $0.1 \mathrm{M} \mathrm{PB}$ and mounted with aqueous medium (Fluorsave ${ }^{\circledR}$ ).

\section{QuANTITATIVE ANALYSIS OF HISTOLOGICAL AND IMMUNOHISTOCHEMICAL SAMPLES}

In the sections stained with hematoxylin-eosin/toluidine blue, 246 photographs were taken, 3 sections were selected per sample and 3-4 photos were taken per section, depending on the presence of ON, retina, or both. Finally, 80 photographs of the control group, 84 photographs of the EAE group and 82 photographs of the EAE-MSC group were analyzed. RGC numbers per unit length were measured at an average distance of $300 \mu \mathrm{m}$ on both sides of the ON entrance site, a reference area with less anatomical variability to allow reproducible counts in different samples. RGCs were counted manually. To study endogenous inflammation, resident and reactive glial cells were detected with anti-GFAP antibodies. Total GFAP positive cells per micron were counted in 3 sections/animal per group, and the differences were analyzed.

\section{QUANTITATIVE ANALYSIS BY ELECTRON MICROSCOPY: G-RATIO AND AXONAL DENSITY}

For quantitative studies of transmission electron microscopy (TEM), the ONs were cross-sectioned. Sections with both $\mathrm{ON}$ and retina were selected, and then ultra-thin sections, of $70-80 \mathrm{~nm}$, were obtained in resin (Leica EM-UC6) to complete the morphological-ultrastructural analysis by electron microscopy (Transmission electron microscopy FEI-Tecnai-Spirit-G2, Oregon, USA).

The G-ratio was obtained as the ratio between the internal axonal diameter (excluding myelin) and the total outer diameter (including the myelin sheath). In the ultrafine sections of the ON, more than 100 axons per group were studied and classified as normal (G-ratio: $0.740 .84)^{12}$, remyelinating axons (G-ratio: $0.85-0.94$ ) and axons with severe myelin damage (G-ratio: 0.951). We obtained 103 micrographs by transmission electron microscopy (48 from the control group, 25 from the EAE group and 30 from the EAE-MSC group). Axonal density was calculated as the number of axons per square micrometer in four sections per animal. This measure was obtained as the average of two blinded independent observers (RGG, LCN).

\section{Statistical analysis}

Because our sample size excluded parametric testing, we performed the Mann-Whitney $U$ test to study the statistical significance between experimental groups. The differences between groups were considered significant if the $p$-value was $<0.05$. For comparisons between more than two groups, we used the Kruskal-Wallis test.

\section{Results}

\section{Animals treated with adult mesenchymal stem cells had a longer disease-free period compared to untreated animals}

Animals with EAE experienced the first clinical signs from day 7 to day 19 after immunization. These symptoms consisted of motor deficits secondary to spinal cord injury and were progressive, since our model reproduced a chronic course ${ }^{9}$. The onset consisted of a focal deficit with loss of the muscular tone of the tail, followed by an ascending progressive paresis that led to the endpoint criteria at different time points (the animals were euthanized due to ethical reasons). The clinical course was variable, with an average life expectancy of 57 days (range 30-70). Although there was a delay in the onset of the disease in the EAE-MSC group compared to the EAE group (10 vs. 13 days), $p$ values were not statistically significant $(p=0.07)$. At one point (45 days after immunization), the animals in the $E A E$ group reached an average maximum disability of 3.5 points, where it was evident that the disease was established with severe motor involvement and paralysis 


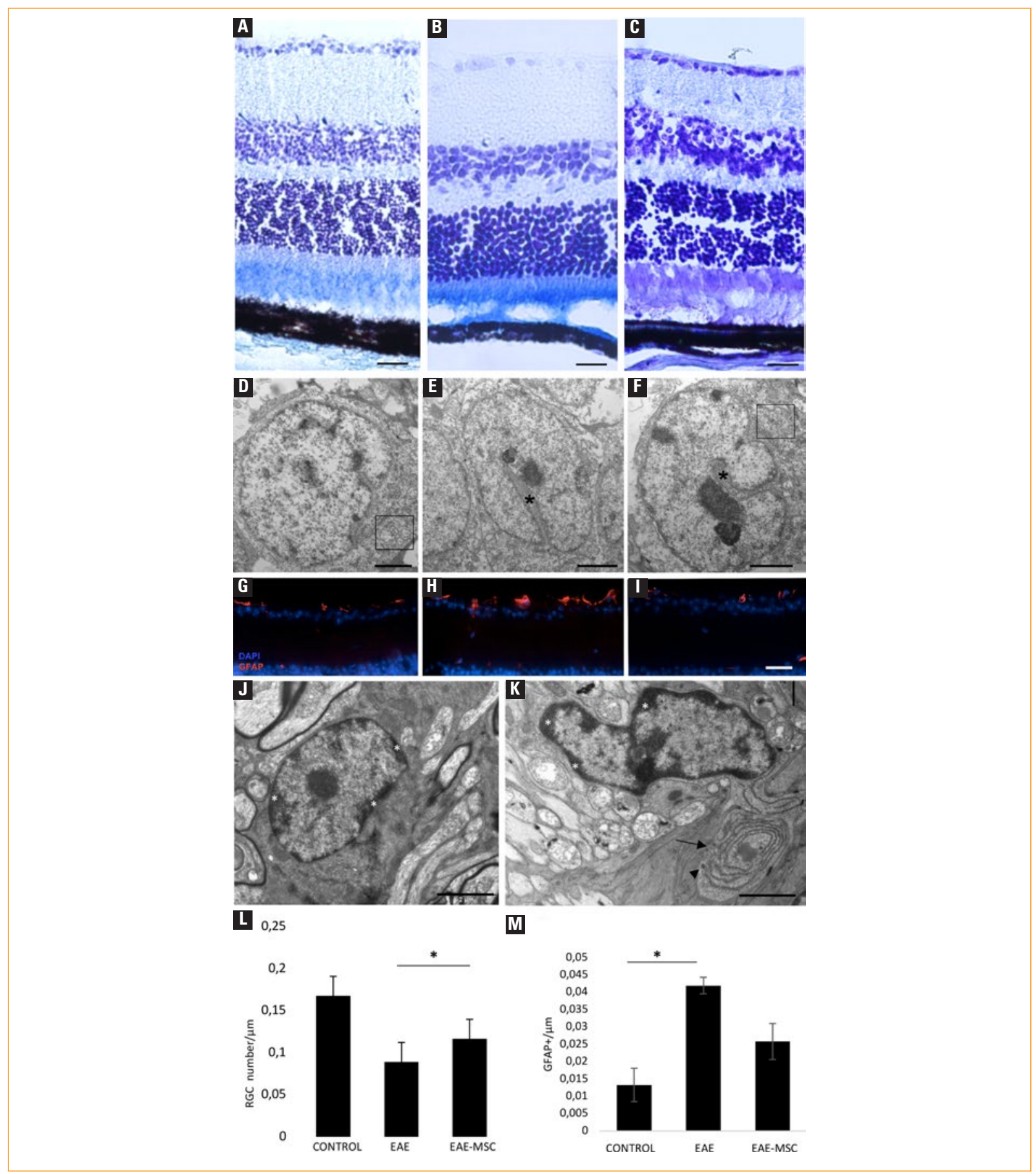

Figure 1. Comparative histological and ultrastructural study of the retina. A-C: toluidine blue-stained retinal cryostat sections in the control group (A), experimental autoimmune encephalitis group (EAE) (B) and EAE group treated with adult mesenchymal stem cells (EAE-MSC) (C) (10 $\mu \mathrm{m}$ scale). D-F: micrographs, ultrafine sections, ultrastructural study of retinal ganglion cells (RGCs) in the control group (D), showing large and rounded nucleus, dispersed chromatin, abundant endoplasmic reticulum and characteristic microtubules (box), EAE group (E) and EAE-MSC group (F). The morphology of RGCs is altered in the treated group with $E A E$, and the MSC group shows invaginated nuclei (asterisk) and a more disorganized cytoskeleton (dashed box) (2 $\mathrm{mm}$ scale). G-I: glial fibrillary acidic protein (GFAP) (red) expression in the RGC layer in the control group (G), EAE group (H) and EAE-MSC group (I) (20 $\mu \mathrm{m}$ scale). J,K: microglia cells are characterized by an irregular nucleus, with chromatin condensation in the periphery (asterisks), large elongated cisterns (arrow) and secondary lysosomes (arrowhead) ( $2 \mu \mathrm{m}$ scale). L: quantitative evaluation of RGC per $\mu \mathrm{m}$ in the three groups studied. M: quantitative evaluation of the number of glial cells (GFAP+) in the retina per $\mu \mathrm{m}$. 
of all limbs, making difficult for the animal to obtain food and water, while the animals in the group treated with aMSCs had a maximum score of 2.5 points, with a disease manifested as paralysis of two limbs (both hind or one front and one hind). All animals met the endpoint criteria and were euthanized.

\section{Immunization with experimental autoimmune encephalitis led to morphological changes and decreased the number of retinal ganglion cells with a favorable effect after administration of adult mesenchymal stem cells}

aMSCs were transfected with a plasmid expressing GFP in order to detect grafted aMSCs by immunofluorescence. We could not detect aMSCs as GFP+ cells in our retinal or ON samples; however, we observed changes in neuronal viability, myelination and local inflammation, as we describe in more detail.

In both EAE and treated groups, the retinal morphology at low magnification did not differ from that of the control mice (Figs. 1 A-C). However, TEM showed that RGCs in the control group were large cells with rounded nuclei and a central nucleus with dispersed chromatin, abundant rough endoplasmic reticulum and microtubules (Fig. 1 D). In contrast, in the EAE and treated groups, the RGCs cytosol was darker, with smaller nuclei and with large, evident invaginations that reached the center of the nucleus (Fig. $1 \mathrm{E}$ ) and with sphericity loss due to acquisition of a cornered shape (Fig. $1 \mathrm{~F}$ ). They showed a disorganized cytoskeleton that suggested damage of RGCs (Figs. $1 \mathrm{E}$ and F). Adjacent glial cells characterized by light cytosol, intermediate filaments and invaginated nuclei, were observed more frequently in the EAE and treated groups compared to the control group. Microglial cells with a dark cytosol and invaginated form, long cisterns and lysosomes were more abundant in the studied regions of immunized mice (Figs. $1 \mathrm{~J}$ and $\mathrm{K}$ ). Both types of cells were also observed by immunohistochemistry against GFAP, a protein of the intermediate filaments present in astrocytes (Figs. $1 \mathrm{~L}$ and $\mathrm{M}$ ).

RGCs were morphologically altered in immunized mice, but to assess whether morphological changes were related to cell loss, we quantified the number of RGCs per unit length in longitudinal retinal sections in all groups. In accordance with our previous data, the number of RGCs in the control group showed an average of $0.1678 \mathrm{RGC} / \mu \mathrm{m}$. The EAE group and the aMSC-treated group showed a significant decrease in the number of RGCs, with values of $0.0891 \mathrm{RGC} / \mu \mathrm{m}$ $(p=0.000035)$ and $0.116(p=0.0002) R G C / \mu m$, respectively, compared to control mice. When the RGC numbers between the EAE and the aMSC-treated group were compared, the differences were also significant $(p=0.01)$ (Fig. $1 \mathrm{~L})$.

Immunohistochemistry against GFAP showed an increase in GFAP+ cells in the EAE group (0.0419 GFAP+ cells $\mu \mathrm{m})$ and in the treated group $(0.0322$ GFAP+ cells $/ \mu \mathrm{m})$ compared to the control group $(0.0132$ GFAP+ cells $/ \mu \mathrm{m}$ ) (Fig. $1 \mathrm{M})$. These results showed a significant increase in GFAP+ cells in immunized animals compared to control mice $(p=0.038)$ and a partial response to aMSC treatment that, however, did not reach statistical significance $(p=0.068)$.

\section{Endogenous inflammation and demyelination of the optic nerve of immunized mice was partially rescued with intravenous administration of adult mesenchymal stem cells}

Morphological examination of the longitudinal sections of the ON with histological staining at low magnification, showed that in the EAE group, the nerve had irregular borders with narrow demarcated regions that corresponded to areas of higher cell density (arrows Fig. $2 \mathrm{C}$ ), compared to the absence of ON narrowing in the control group (Fig. $2 \mathrm{~A}$ ).

These data were confirmed by TEM, since the axons in the $\mathrm{ON}$ of the immunized mice showed signs of degeneration such as a dark cytosol with an interrupted microtubule network in the axoneme and myelin spheroid bodies, instead of concentric regular myelin sheaths, as observed in control mice (Fig. 2 D); in addition, abundant reactive astrocytes were observed in the intercellular space between damaged myelinated axons (asterisk in $2 \mathrm{D}$ ).

aMSC treatment decreased the degenerative signs in myelin and axons, showed less glial cell infiltrates in the damaged $\mathrm{ON}$ and resulted in an intermediate state between the control and treated mice. To determine these changes quantitatively, we obtained cross sections of the ON that were stained with toluidine blue to count cells per unit area $(\mu \mathrm{m})$ (Fig. 2). In the control group, the average number of cells per unit area was of $1.86 \mathrm{cells} / \mu^{2} \mathrm{~m}^{2}$, while in the EAE group, it was of 7.99 cells $/ \mu \mathrm{m}^{2}$. aMSC treatment resulted in $3.69 \mathrm{cells} / \mu^{2} \mathrm{~m}^{2}$. Statistical studies showed a significant difference between the three groups $(p<0.0001)$. Subsequently, the specific differences between the mean 


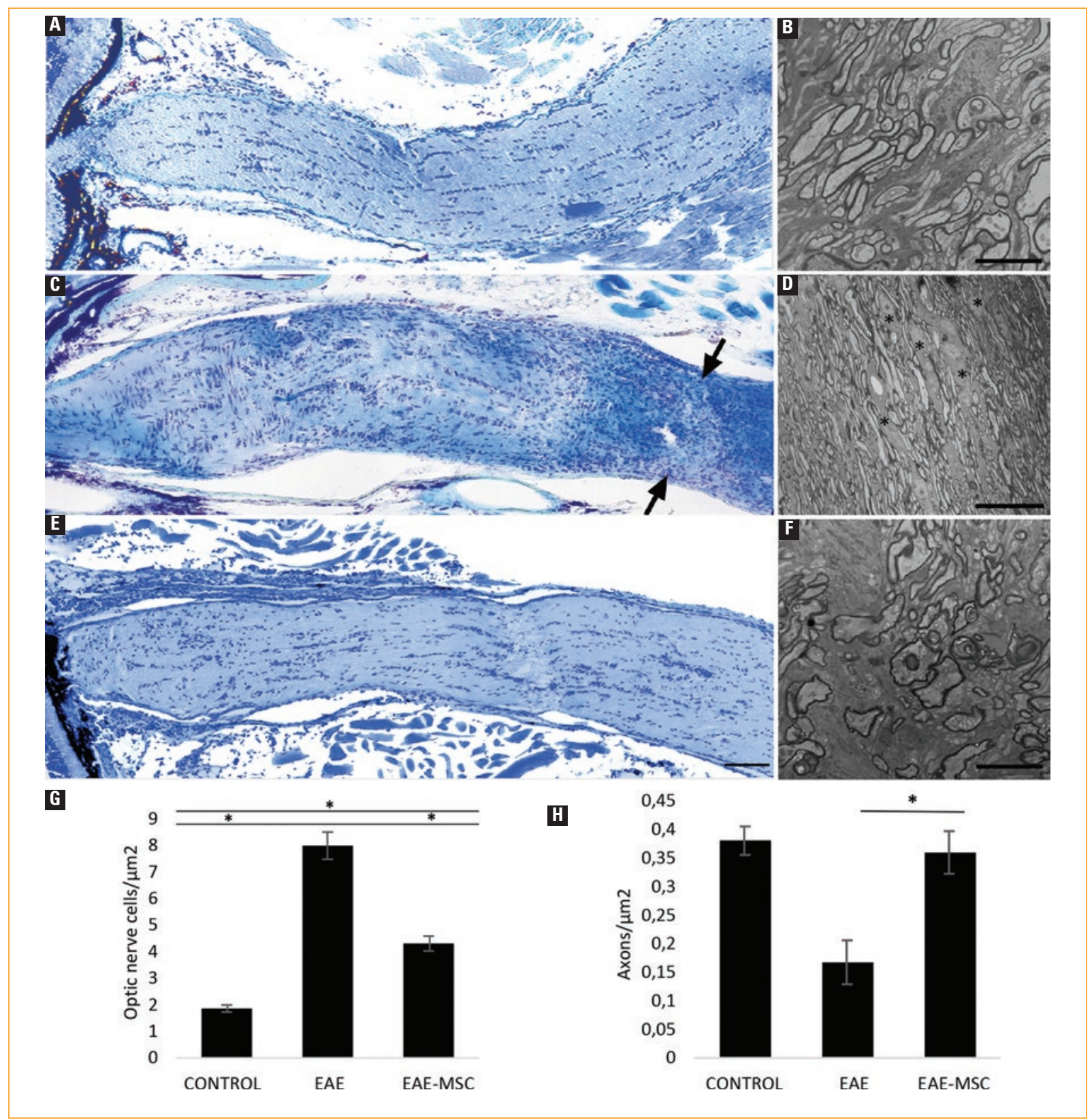

Figure 2. Comparative histological and ultrastructural study of the optic nerve (ON). A-E: toluidine blue stained ON cryostat sections of the control group (A), experimental autoimmune encephalitis group (EAE) (C) and EAE group treated with adult mesenchymal stem cells (EAE-MSC) (E); black arrows: focal irregular borders with increased cell density, $200 \mu \mathrm{m}$ scale. B-F: ultrastructural study of ON axons in the control group (B), EAE group (D) and EAE-MSC group (F); asterisk: astrocytes that fill the spaces due to myelin loss, showing their cell bodies and expansions. These reactive astrocytes are large, occasionally multinucleated cells, with abundant intermediate filaments distributed in the cytoplasm. The nuclei are large, slightly irregular, with loose chromatin, scale $5 \mu \mathrm{m}$ (B), scale $20 \mu \mathrm{m}$ (D) and scale $5 \mu \mathrm{m}$ (F). G: cell density in the $0 \mathrm{~N}$ per $\mu \mathrm{m}^{2}$. Significant differences between all groups $(p<0.05)$. H: axonal density (number of axons per $\mu \mathrm{m}^{2}$ ). Statistically significant differences favoring the EAE-MSC group ( $<<0.05)$.

cellularity in both groups (EAE and EAE-MSC) were compared using the Mann Whitney $U$ test, which was also statistically significant $(p=0.0143)$. To calculate axonal density (Fig. $2 \mathrm{H}$ ), we counted the number of axons per unit area. While in the control group we obtained an axonal density of 0.38049 axons $/ \mu \mathrm{m}^{2}$, in the EAE group, the value obtained was of 0.16745 axons $/ \mu \mathrm{m}^{2}$, and this decrease was significant 


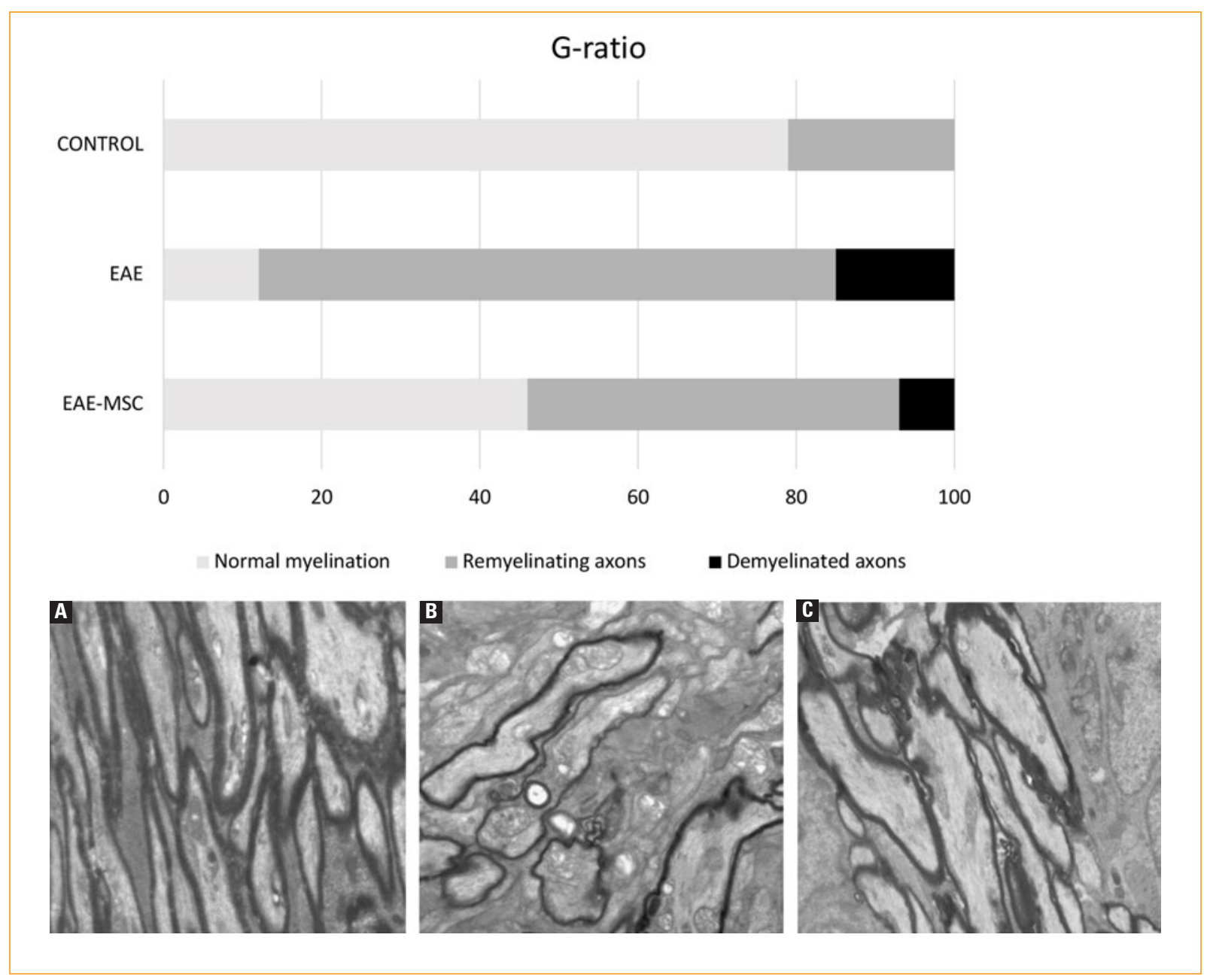

Figure 3. Study of the degree of myelination. G-ratio. EAE-MSC mice show a demyelination that was recovered after treatment with aMSCs. A-C: axonal ultrastructure study. A: control: axons with homogenous myelination: normal myelination. B: EAE: disorganized axons with great demyelination. C: EAE-MSC: disorganized remyelinating axons, $5 \mu \mathrm{m}$ scale.

$(p=0.0003)$. The comparison of axonal density between the EAE and the aMSC-treated group $(0.3598$ axons $/ \mu \mathrm{m}^{2}$ ) was statistically significant, favoring the treated group ( $p=0.0251$ ). The G-ratio in EAE-MSC mice showed a demyelination that recovered after treatment with aMSCs (Fig. 3). In the control group, $79 \%$ of the axons were normally myelinated, $21 \%$ of the axons were remyelinated and none of the axons studied were demyelinated. In contrast, in the EAE group, we found $12 \%$ of normal axons, $73 \%$ of remyelinated axons and $15 \%$ of axons with acute myelin damage. EAE-MSC mice exhibited $46 \%$ of axons with normal myelin, $47 \%$ with remyelination and $7 \%$ demyelinated. It should be noted that, if we consider the percentage of axons that had suffered any damage (grouping the remyelination and demyelination processes) with G-values above 0.84 , the total of axons altered was of $88 \%$ in the $E A E$ group compared to $54 \%$ in the EAE-MSC group.

\section{Discussion}

In this work we studied the possible effect of aMSCs, evaluated that an intravenous infusion with aMSCs may improve inflammatory, demyelinating and neurodegenerative damage in both the retina and the $\mathrm{ON}$, while, unfortunately, the clinical effect was not sufficient to stop the progression of the disease.

On the other hand, published studies on different models of axonal damage (transient retinal ischemia ${ }^{13}$ or $\mathrm{ON}$ axotomy ${ }^{14}$ ) described that the interruption of RGC axons caused retrograde axonal degeneration that induced RGC death ${ }^{15}$. In our work we observed a significant loss of RGCs in EAE mice compared to the control group, which could be the result of documented axonal damage of the $\mathrm{ON}$ and Wallerian degeneration. Another possibility would be that, as the inflammation of the $\mathrm{ON}$ and the structural damage seemed to be 
more relevant, the death of RGCs was caused by the local toxic effect of the microglia, which was increased in the EAE and EAE-MSC groups, as reported in other models of ocular inflammation ${ }^{16}$. The treatment with aMSCs improved the inflammation of the ON, decreased the loss of RGCs, but no "rescue" effect was observed for RGCs; this could be due to a better access of the aMSCs to the ON through the blood brain barrier $^{17}$ or a delayed effect of the decrease in inflammation of the ON due to aMSCs in Wallerian degeneration of the retina.

aMSCs represent a population of multipotent stem cells that, when administered intravenously, have the ability to migrate and graft in places where tissue damage and inflammation occur. We describe that aMSCs administered intravenously had the ability to decrease inflammatory infiltrates and reduce myelin loss and axonal damage. This effect was not related to aMSC grafting, because we could not find green fluorescent aMSCs in our samples. This could be due to several causes, including sequestration in other organs (liver, lungs), immune rejection and/or apoptosis once in the CNS. According to published studies, aMSCs administered by the tail vein in mice initially accumulate in the lungs and gradually pass to the liver, spleen, kidney and bone marrow in the first 48 hours ${ }^{18,19}$. Rochefort et al. found accumulation in the lung of $50-60 \%$ of aMSCs one hour after the injection, with a subsequent decrease to approximately $30 \%$ three hours after the injection ${ }^{20}$. The same group injected aMSCs intravenously in humans and also showed a high pulmonary uptake within 30 minutes $^{21}$. Several studies have demonstrated the low immunogenicity of aMSCs since they do not express MHC-II, that prevents the recognition by dendritic cells and $T$ lymphocytes. However, although they are considered cells that do not cause rejection, when they are exposed to an inflammatory milieu characterized by the presence of high levels of interferon- $\gamma^{22}$, they begin to express HLA-DR (MHC-II), and therefore become immunogenic and are susceptible to rejection. However, our studies and others show that, in addition to the low efficiency for CNS grafting, there is a neuroprotective effect after administration of aMSCs. This effect, called «by-stander», has been described in studies of myocardial infarction after the infusion of aMSCs, where clinical and functional improvement was observed, but it was not possible to identify grafted cells or differentiated myocardiocytes ${ }^{23,24}$. aMSCs are characterized by a high capacity for paracrine communication based on the release of small vesicles or exosomes ${ }^{25}$. Exosomes have been attributed for the effect of aMSCs at distance. It could be that the decrease of the inflammatory response observed in our study may be due to the remote release of exosomes with additional neurotrophic and immunomodulatory action. However, the exact mechanisms are not yet fully understood.

Within the limitations of this study is the reduced sample size and the follow-up of the disease with motor disability scales due to the lack of resources; the follow-up with techniques such as optical coherence tomography ${ }^{26}$ for visualization of retinal structures and the ON in vivo, would have allowed a better monitoring of the disease. It would be interesting in the future to expand this study by overcoming this limitations.

The most interesting contribution of this work is its ophthalmological approach when studying the death of RGCs, as well as the sophisticated techniques used, like electron microscopy.

Finally, we want to emphasize that after the administration of aMSCs, we found a lower loss of RGCs, a decrease of myelin loss and a lower degree of inflammation of the ON; however, it would be advisable to expand the methodology to ensure an immunosuppressive and neuroprotective effect in this model. Since tissue damage due to inflammation is a key process triggered in response to injury and disease, aMSCs could become a treatment for any tissue or organic damage associated with an intense inflammatory activity.

\section{Conclusions}

In this work, we found that after the administration of aMSCs, there is a lower loss of RGCs, a decrease of myelin loss and a lower degree of inflammation of the ON; however, it would be advisable to expand the methodology to ensure an immunosuppressive and neuroprotective effect in this model.

\section{Conflicts of interest}

The authors declare no conflicts of interest.

\section{Ethical disclosures}

Protection of human and animal subjects. The authors declare that the procedures followed were in accordance with the regulations of the relevant clinical research ethics committee and with those of the Code 
of Ethics of the World Medical Association (Declaration of Helsinki).

Confidentiality of data. The authors declare that they have followed the protocols of their work center on the publication of patient data.

Right to privacy and informed consent. The authors have obtained the written informed consent of the patients or subjects mentioned in the article. The corresponding author is in possession of this document.

\section{References}

1. Noseworthy $\mathrm{JH}$. Progress in determining the causes and treatment of multiple sclerosis. Nature. 2000;399:A40-7.

2. Dolati S, Babaloo Z, Jadidi-Niaragh F, Ayromlou H, Sadreddini S, Yousefi M. Multiple sclerosis: Therapeutic applications of advancing drug delivery systems. Biomed Pharmacother. 2017:86:343-53.

3. Dominici M, Le Blanc K, Mueller I, Marini FC, Krause DS, Deans RJ, et al. Minimal criteria for defining multipotent mesenchymal stromal cells. The International Society for Cellular Therapy position statement. Cytotherapy. 2006;8(4):315-7.

4. Galderisi U, Giordano A. The Gap Between the Physiological and Therapeutic Roles of Mesenchymal Stem Cells. Med Res Rev. 2014;34(5):1100-26.

5. De Miguel MP, Fuentes-Julián S, Blazquez-Martínez A, Pascual CY, Aller MA, Arias J, et al. Immunosuppressive properties of mesenchymal stem cells: advances and applications. Curr Mol Med. 2012;12(5):574-91.

6. Yagi H, Soto-gutierrez A, Parekkadan B, Kitagawa Y, Tompkins G, Kobayashi $\mathrm{N}$, et al. Mesenchymal stem cells: mechanisms of immunomodulation and homing. October. 2010;19(6):667-79.

7. Shindler KS, Guan Y, Ventura E, Benett J, Rostami A. Retinal Ganglion Cell Loss Induced By Acute Optic Neuritis in Relapsing Model of Multiple Sclerosis. Mult Scleros. 2006;12(5):526-32.

8. Horstmann L, Schmid H, Heinen AP, Kurschus FC, Dick HB, Joachim SC. Inflammatory demyelination induces glia alterations and ganglion cell loss in the retina of an experimental autoimmune encephalomyelitis model. $J$ Neuroinflammation. 2013;10:1-12.

9. Feliciano-Sanchez A, García-Gil R, Cubas-Nuñez L, Castillo-Villalba J, Fuentes-Maestre J, Fil M, et al. Development and optimisation of an animal model for the study of ganglion cells in degenerative diseases of the retina and optic nerve. Arch la Soc Española Oftalmol. 2019;94(6):263-72.

10. Pierini M, Dozza B, Lucarelli E, Tazzari PL, Ricci F, Remondini D, et al. Efficient isolation and enrichment of mesenchymal stem cells from bone marrow. Cytotherapy. 2012;14(6):686-93.
11. García-Contreras M, Vera-Donoso CD, Hernández-Andreu JM, García-Verdugo JM, Oltra E. Therapeutic potential of human Adipose-Derived Stem Cells (ADSCs) from cancer patients: A pilot study. PLoS One. 2014;9(11):e113288.

12. Chomiak $T, H u B$. What is the optimal value of the g-ratio for myelinated fibers in the rat CNS? A theoretical approach. PLoS One. 2009;4(11):e7754.

13. Sellés-Navarro I, Villegas-Perez MP, Salvador-Silva M, Ruiz-Gómez JM, Vidal-Sanz M. Retinal ganglion cell death after different transient periods of pressure-induced ischemia and survival intervals: A quantitative in vivo study. Investig Ophthalmol Vis Sci. 1996;37(10):2002-14.

14. Borsello T, Mottier V, Castagné V, Clarke PGH. Ultrastructure of retinal ganglion cell death after axotomy in chick embryos. J Comp Neurol. 2002;453(4):361-71.

15. Galindo-Romero $C$, Avilés-Trigueros M, Jiménez-López M, Valiente-Soriano FJ, Salinas-Navarro M, Nadal-Nicolás F, et al. Axotomy-induced retinal ganglion cell death in adult mice: Quantitative and topographic time course analyses. Exp Eye Res. 2011;92(5):377-87.

16. Guan $Y$, Shindler KS, Tabuena $P$, Rostami AM. Retinal ganglion cell damage induced by spontaneous autoimmune optic neuritis in MOG-specific TCR transgenic mice. J Neuroimmunol. 2006;178(1-2):40-8.

17. Hu P, Pollard J, Hunt N, Chan-Ling T. Microvascular and cellular responses in the retina of rats with acute experimental allergic encephalomyelitis (EAE). Brain Pathol. 1998;8(3):487-98.

18. Daldrup-Link HE, Rudelius M, Metz S, Piontek G, Pichler B, Settles M, et al. Cell tracking with gadophrin-2: a bifunctional contrast agent for MR imaging, optical imaging, and fluorescence microscopy. Eur J Nucl Med Mol Imaging. 2004;31(9):1312-21.

19. Gao J, Dennis JE, Muzic RF, Lundberg M, Caplan Al. The dynamic in vivo distribution of bone marrow-derived mesenchymal stem cells after infusion. Cells Tissues Organs. 2001;169(1):12-20.

20. Rochefort GY, Vaudin P, Bonnet N, Pages J-C, Domenech J, Charbord P, et al. Influence of hypoxia on the domiciliation of mesenchymal stem cells after infusion into rats: possibilities of targeting pulmonary artery remodeling via cells therapies? Respir Res. 2005;6:125.

21. Kang WJ, Kang H-J, Kim H-S, Chung J-K, Lee MC, Lee DS. Tissue distribution of $18 \mathrm{~F}-\mathrm{FDG}$-labeled peripheral hematopoietic stem cells after intracoronary administration in patients with myocardial infarction. J Nucl Med. 2006;47(8):1295-301.

22. Ryan JM, Barry F, Murphy JM, Mahon BP. Interferon- $\gamma$ does not break, but promotes the immunosuppressive capacity of adult human mesenchymal stem cells. Clin Exp Immunol. 2007;149(2):353-63.

23. Mazhari $\mathrm{R}$, Hare JM. Mechanisms of action of mesenchymal stem cells in cardiac repair: potential influences on the cardiac stem cell niche. Nat Clin Pract Cardiovasc Med. 2007;4 Suppl 1:S21-6.

24. Ankrum JA, Faii Ong J, Karp JM. Mesenchymal stem cells: immune evasive, not immune privileged. Nat Biotechnol. 2014;32(3):252-60.

25. Yu B, Zhang X, Li X. Exosomes derived from mesenchymal stem cells. Int J Mol Sci. 2014;15(3):4142-57.

26. Fischer MD, Huber G, Beck SC, Tanimoto N, Muehlfriedel R, Fahl E, et al. Noninvasive, in vivo assessment of mouse retinal structure using optical coherence tomography. PLoS One. 2009;4(10):e7507. 